\title{
LA-UR $93-0301$
}

CCHA-

FEEEIVED

FEB 111993

OSTI

Los Alamos National Laboratory is operated by the University of California tor the United States Depertment of Energy under contract W.7405.ENG.36

LA-UR - -93-301

DE93 007367

TITLE: PREPROCESSING REMOTELY-SENSED DATA FOR EFFICIENT ANALYSIS AND CLASSIFICATION

AUTHOR(S): $\quad$ Patrick M. Kelly and James M. White

SUBMITTED TO: Intemational Society of Optical Engineering Conference

Orlandn, Florida

April 12-16, 1993

\section{DISCLAIMER}

\begin{abstract}
This report was prepared as an account of work sponsored by an agency of the Unitod States Government. Neither the United Siates Government nor any agenry thereol, nor uny of their employees, makes any wurranty, express or implied, or ussumes any legal liability or responaibility for the accuracy, completeness, or usefulness of any information, apparatus, product, of process disclosed, or represents that its use would not infringe privately owned rights. Roference herein to any specilic commercial product, process, or service by trade name, trademark, manufacturer, or otherwise does not necessurily constitute or imply its endorsement, recommendation, of favoring by the Unitod Staten (jovernment or any agency thereof. The viewa and opinions of authors expremed herein do not necesuarily stste of reflect those of the United Statew Government or any agency thereof.
\end{abstract}

By ecceptance of this article, the publisher reognizes that the U.S. Govemmont rotaine a nonexdusive royalty- free licenee to publiah or reproduce tho publiched torm of this contribution or to allow ofl wre to do so, for U.S. Governmant purposece. 
Preprocessing remotely-sensed data for efficient analysis and classification

Patrick M. Kelly, James M. White

Los Alamos National Laboratory, Computer Research Group

MS B-265, Los Alamos, NM 87545

\begin{abstract}
Interpreting remotely-sensed data typically requires expensive, specialized computing machinery capable of storing and manipulating large amounts of data quickly. In this paper, we present a method for accurately analyzing and categorizing remotely-sensed data on much smaller, less expensive platforms. Data size is reduced in such a way as to retain the integrity of the original data, where the format of the resultant data set lends itself well to providing an efficient, interactive method of data classification.
\end{abstract}

\title{
1. INTRODUCTION
}

A Landsat Thematic Mapper (TM) quarter scene consists of approximately 12 million pixels, each being represented by seven spectral reflectance values between 0 and 255 . Each quarter scene, therefore, occupies 84 megabytes of storage, and performing even simple data mauipulatione for analysis or display purposes requires a large number of operations. By preprocessing the data by a technique known as vector quantization or clustering, computational requirements necessary for image analysis and manipulation are greatly reduced.

The advantages to clustering large data sets are numerous. Many times when scientists work with multispectral image data, they are interested in grouping together apts of similar data - something that clugtering algorithme do automatically. Clustered data also has a number of properties that gimplify data analysis and categorization. Data compression is a very desirable by-product of the clustering process, reducing the computational resources necessary to manipulate the data. Additionally, because pixels belonging to the same cluster are intrinsically associated with one another, sets of pixels in an image which share common characteristica can be manipulated simultaneously. Statistics for each cluater can easily be calculated during the clustering process, allowing many properties of the original data to be retained. For many applications, we have found that once clustering has been performed, the original dato is no longer needed.

Each pixel in an image is commonly categorized according to its apectral signature. Many mothods are used for clasaifying multispectral data, including both supervised and unsupervised clasaification methods (1, 2). When using supervised methods for data classification, user selects training areas representative of seversl types of land cover, and a clasoifier in developed to discriminate between difierent classes. This clasoifier in then used to calegorize the remaining pixels in the scene. Numerous pattern recognition algorithmn of this type exist, including nearest neighbor algorithms, discriminant function techniques, artifleia neural networkn, and statistical methods. An overview of thene techniques can be found in atandard paltern recognition textbooka [3, 1]. Statistical mothods auch a maximum likelihood classiflern [3] have always been popular for this type of problen. In general, although these techniques often work well, they are very time conourning both in computer time and operntor offort. Additionally, they do not tend to allow cany classifler adjustments (or "line-luning") for the nystein.

Unlike nupervised methods of classiftcation, which require n uant to define training actn, unsupervised techniquen require no training mats at all. 'They inatand attempt to automaticaliy find the underlying atructure of multi-

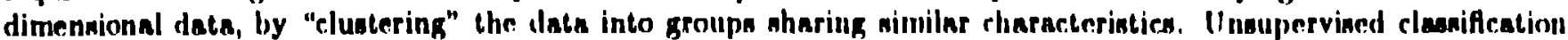

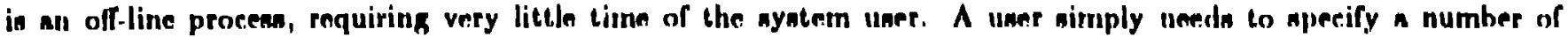
cluatern to flnd, and allow the clawifleation program to do the reat. 'I'hin technigue anmurnen, however, that the number of natural eategorien prenent in the dale in known a priori, with date from different calegory elustern being well-reparated. 


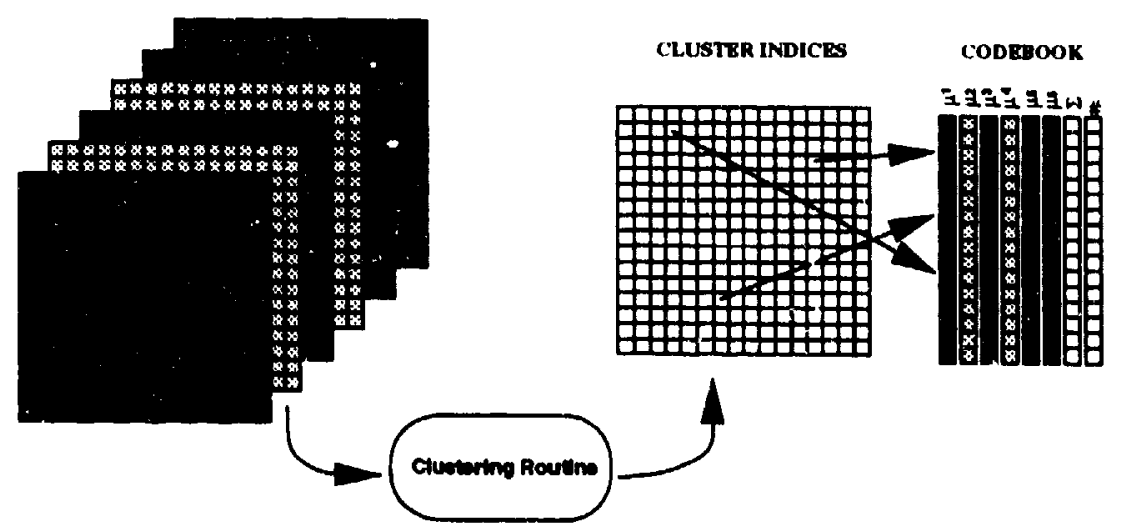

Figure 1: Clustered Reprosentation of Multispectral Image Data

When using clustering methods for analyzing multispectral data, many people attempt to define a relatively small number of clusters - between 5 and 100 clusters, for example. Our technique relies on the fact that many clusters (between 256 and 4096) can be defined for the data. The method of data analysis and classification presented in this paper first preprocesses the data using a fast clustering algorithm. We cluster the data using a relatively large number of clusters (as compared to the number of categories we wish to define for the data), and then use the clustered data for analysis and classification. For many applications, there is no need for the original data after clustering is performed. Using the clustered data, we can efficiently manipulate computer wisplays as well as analyze and categorize data.

\section{CLUSTERING METHODOLOGY}

The basic principle of clustering (or vector quantization) is to take an original image (for our example, containing around 12,000,000 pixels with each pixel being represented by a seven-dimensional vector), and represent the same image using only a small number of unique pixel values. A codebook of $\mathrm{N}$ "best pixel values" to represent the image must first be generated by some itcrative method (the "construction" phase of the clustering algorithm). Once we have generated these values, we step through the original image and assign cach pixel to the cluster of the closest match existing in our codebook (the "projection" phase of the clustering algorithm). Figure 1 shows the clustered image representation, as compared to the original image representation.

In processing the data this way, two things have occured. First, we have reduced the volume of data needed to represent the image by a factor of seven. 'This is reflected by the fact that we now need only a aingle band of image data which contains indices into the codebook of reference vectors. Second, we have done a preliminary classification of the data; similar pixels in the image are now intrinsically associated with one another.

Since we would like the cluatered data to adequately reprenent the original data, the selection of the codebook vectors is very important. By increasing the number of clusters, the accuracy of image representation can be improved. Depending on the nppliention, we une betwenn 256 and 4096 ilustern for n typical TM qunrter meene. 'The time repuired to cluster the image increases as the number of clusters increnses. After clustering hisw provided a set of clusters, the statistics for each clunter are computed and atored in the codebook along with the cluster reference vectore. This is an important atep because irom these atatiatics, the combined statinties of the original data can enily be computed

An nu extrn step. the cluater indicen nee acorted necording to valuen atored in the menn vertorm. Before thin atep in performed, the ningle two-dimennionnl band of clunter indicen reprenenting the data in mensiuglese unlens it is awocinted with its codebook. By norting the clusters arcording to valuen in aingle dimenmion, or by the num of

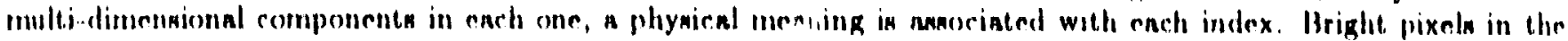


original data set will be associated with larger cluster indices than the darker pixels. The result will be an image which, when not associated with its codebook, can easily be displayed as a black and white image of the current scene.

\section{CLUSTERING ALGORITHM}

Many types of clustering methods have been developed and analyzed for use with different types of data [3,5]. In general, many of these algorithms attempt to find a partitioning of a given data set that minimizes a predetermined cost function. The k-means clustering algorithm [4] attempts to minimize a squared error cost function by manipulating a set of $k$ cluster centers. In particular, this algorithm tries to partition the data into $k$ clusters, denoted by $C_{i}$, with the representative vector for each cluster $\left(\dot{x}_{i}\right)$ being defined as the within-cluster mean:

$$
\dot{x}_{i}=\frac{1}{N} \sum_{x, \in C_{1}} x_{j}
$$

This algorithm iteratively moves vectors between clusters in such a way as to minimize the total squared error:

$$
\text { Error }=\sum_{i=1}^{k} \sum_{s, \in C_{1}}\left\|x_{j}-\hat{x}_{i}\right\|^{2}
$$

This algorithm, however, becomes painfully slow when using very large data sets. One basic problem is that a tremendous number of vector distance calculations must be performed during both the "construction" and "projection" phases of the algorithm. Several methods have been developed to improve this situation [6, 7, 8]. Many of these schemes work very well in lower-dimensional spaces, but. still tend to have a difficult time as the dimension of the problem and number of clusters increase.
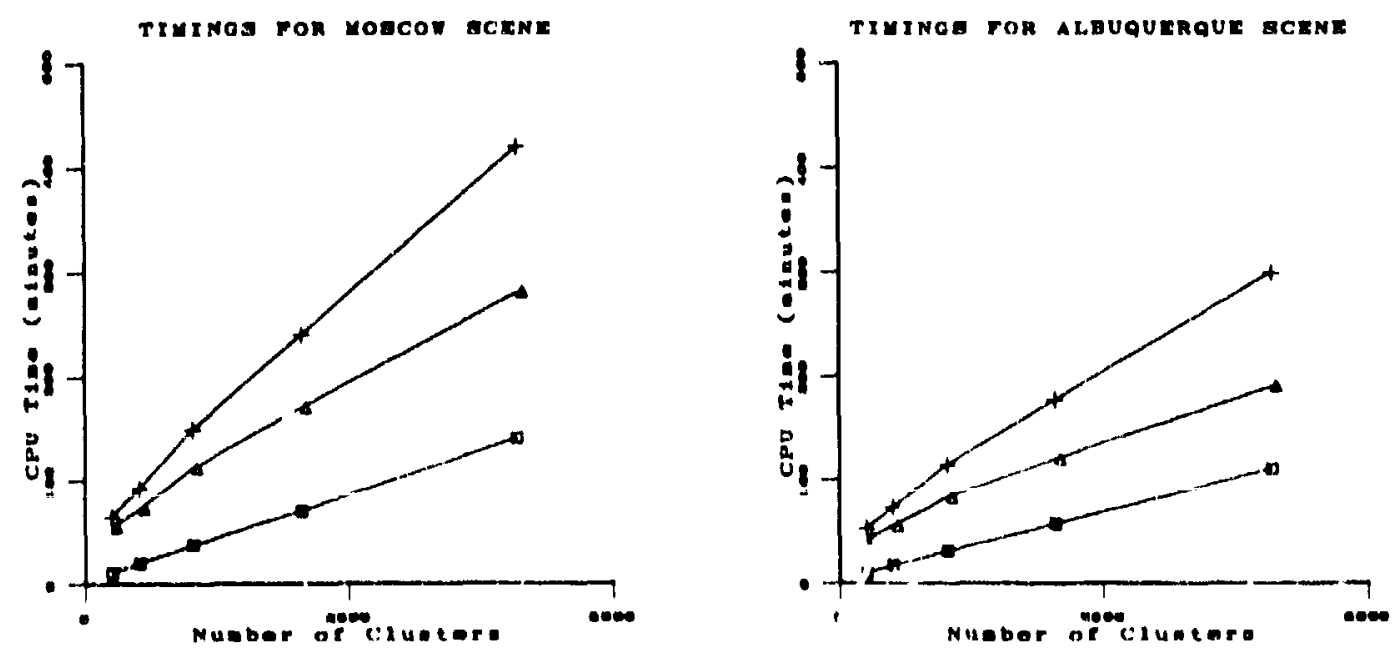

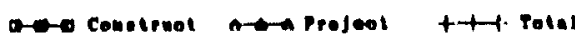

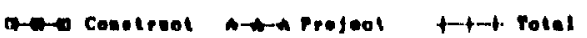

Figure 2: (PU Timinge for Moserow and Albuquerquen Sernes 
We use a version of the nearest neighbor algorithm proposed in [9], where cluster positions are sorted along one of the axes for the data. This algorithm, like many others, does not continue to work effectively as the problem dimension increases. To combat this, we use the first principal component of the data as the axis on which to do the sort. This axis gives the best possible separation of the data.

Another major hindrance with the k-means algorithm is that the "construction" phase can require many passes through our tremendous data set to build the codebook. But this extra work is not necessary; the fata has large amounts of redundant information. We use a monte carlo method for passing through the data, and only sample about 10 percent of the actual data.

Our overall clustering technique yields the same results as the $k \cdot$ means algorithm, but converges much faster Clustering times for a TM quarter scene (seven-dimensional data, 3000 rows by 3500 columns) of the Moscow and Albuquerque areas are shown in Figure 2. These were calculated on a desktop SUN SPARCstation IPX with 16 $\mathrm{MB}$ of RAM, and show CPU time required for clustering the data into 256, 512, 1024, 2048, and 4096 clusters. It is important to note that the execution time grows linearly as the number of clusters is increased. This is not a property of the algorithm in general, but it has seemed to hold true for the vast majority of real-world multispectral data sets (as well as most others) that the authors have encountered.

\section{DATA ANALYSIS AND CLASSIFICATION}

Once our TM scene has been clustered, it requires only one-seventh of the storage originally required, and the new clustered representation provides an opportunity to use common computer displays very efficiently. Since there are only $\mathrm{N}$ unique "vectors" representing the image, it takes on the order of $\mathrm{N}$ operations to manipulate the data as compared to 12 million operations before the clustering was performen. Calculating the vegetation vigor of pixels in a TM scene shows an example of the savings incurred by clustering. One measure of vegetation vigor commonly used by remote sensing specialists is (Band 4 - Band 3) / (Band $4+$ Band 3). This transformation results in large values (bright pixels) for pixels representing healthy vegetation, and requires three operations at each pixel, or 36 million operations for the entire scene. If we first cluster the data to 256 clusters, we can use 8-bit computer displays effectively. Since the clustered image contains only 256 unique values, 768 operations are required for calculating the vagetation vigor, and the results can be directly mapped into the computer display look-up-tab!es (LUTs). While this is a simple type of operation, the same holds true for very complicated transformations such as the 'lasseled Cap transformation, Karhunen-Loeve transformation, principal component analysis, etc.

Using a display package called SPECTRUM, developed by Los Alamos National Laboratory and the University of New Mexico, we are able to use any desktop workstation running Unix and $X$ windows to analyze and categorize clustered data. Figure 3 shows a clustered TM scene of Moscow as displayed in SPECTRUM. A user can design and Inanipulate a legend that specifies categories of land cover, labels for each category, and pseudocolor representations to be used when categorizing geographic areas in the clustered image. SPECTRUM can manipulate the color map for the computer display using any transformation of the clustered data, and can display clustre positions on n two-dimensional scatter plot. Using these features, users are able to analyze data in a variety of ways. Data cim be categorized by selecting areas with a known type of land cover, causing all associated pixels in the image to be given the same pseudocolor representation. Using the TM dala, for example, a user could locate a wheat field, highlight the pixels in that field, and all other wheat fields in the ontire image would he highlighted immediately. After categorization, an image enn be written out showing the different geographic areas for the recene.

Using the scatter plot, cluater poxitions can he displayed in a two-dimensional space with axes npecified by the user. Scientists can use this feature to interpret end categorize data by looking at different mathemntical trannformationes of the clunter ponitions, while resulten of the procesen are upedated in the currently dinplayed eluntered imagn. 


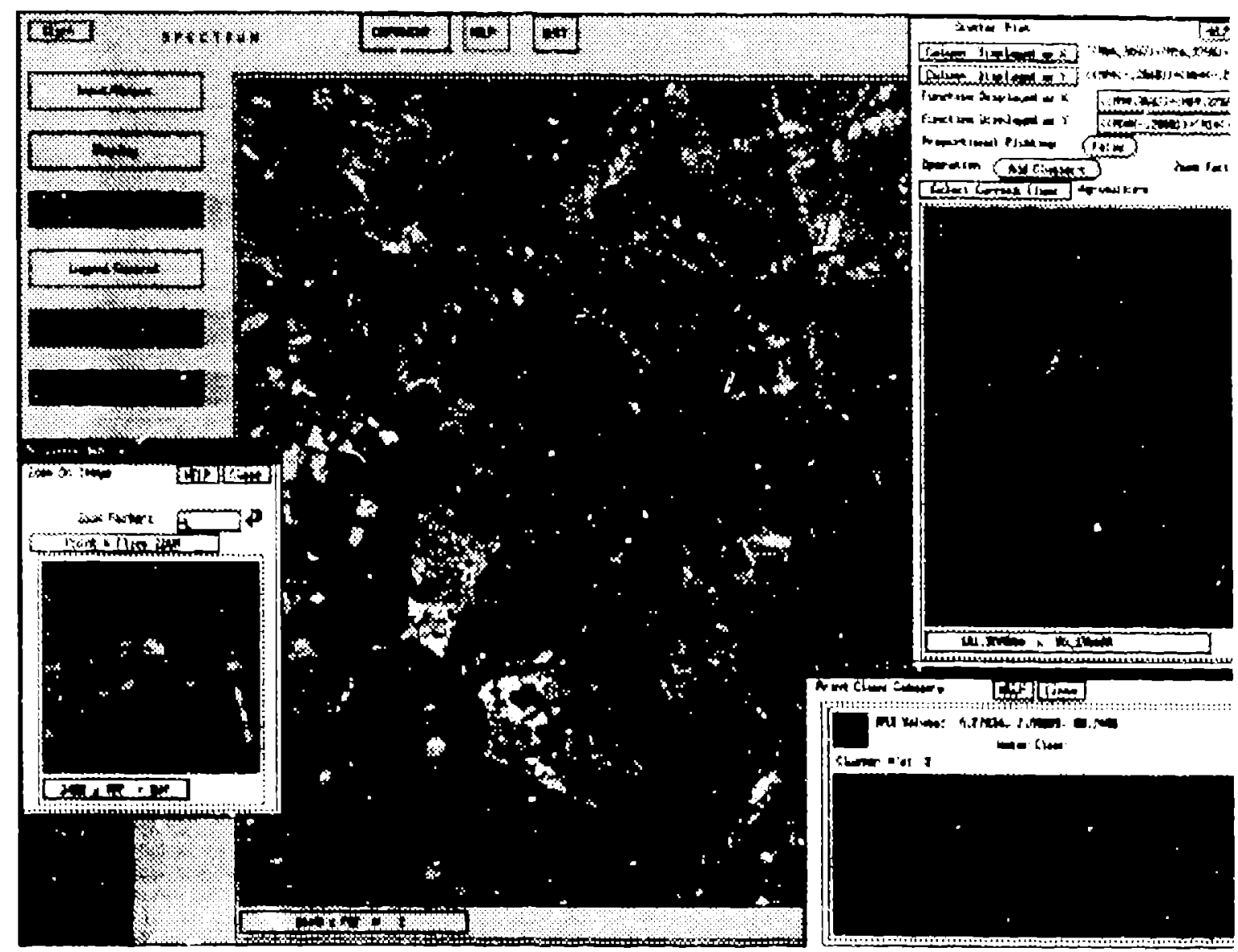

Figure 3: Manipulating Moscow Data with SPECTRUM

\section{ERROR ANALYSIS}

To examine the accuracy of the clustering relative to the number of clusters used, we will look at the average error per pixel introduced by the clustering, the distribution of these errors, and a Chi Square goodness-of-fit measure for different land cover training areas.

An $800 \times 800$ subsection was extracted from the original $3000 \times 3500$ original image of Moscow and the $3000 \times$ 3500 clustered version of the image. An error image was created hy averaging, for the 7 spectral bands, the absolute. difference between the uriginal image and the cluatered image data. In the cluatered image, each pixel is represented hy the mean vector of the cluster to which it is asigned. It should be noted that errors for each of the individual bands is similar in magritude and distribution to the average hetween the 7 spectral bands. The first plot in Figure 1 showe a plot of the average errur per band per pixel and this error $t$ one nlandart deviation. The average crerer for 256 clusters is leso than 2 digital numbers (DN) and drope to less than 1.25) DN average error for 4096 cluaters The maximum error over the subsection was much larger. There were a few popcorn rlouds in the aubsection and the errol for the center pixel in the clouds ranged from about $70 \mathrm{DN}$ for the 256 cluatcrn image to about 30 for the 1096 cluatera inage but these oulliers in the data set were few and it is an enay procens to isolate them an outliern clurilig the cluntering procens. The second plot in Figure 4 showa a histogram of the per pixel errorm. The histograrna alow that even for the 250 cluotero image alunoal all the pixels have an error within $\pm 3 \mathrm{DN}$.

Finally, we chose thre training niten for cach of 1 land cover types in the $3000 \times 3500$ Moscov image repreacnting grans, aoil, waler, and foreat. 'The trainiug aiten were located in the ennter of large uniform land rovern and chomen 

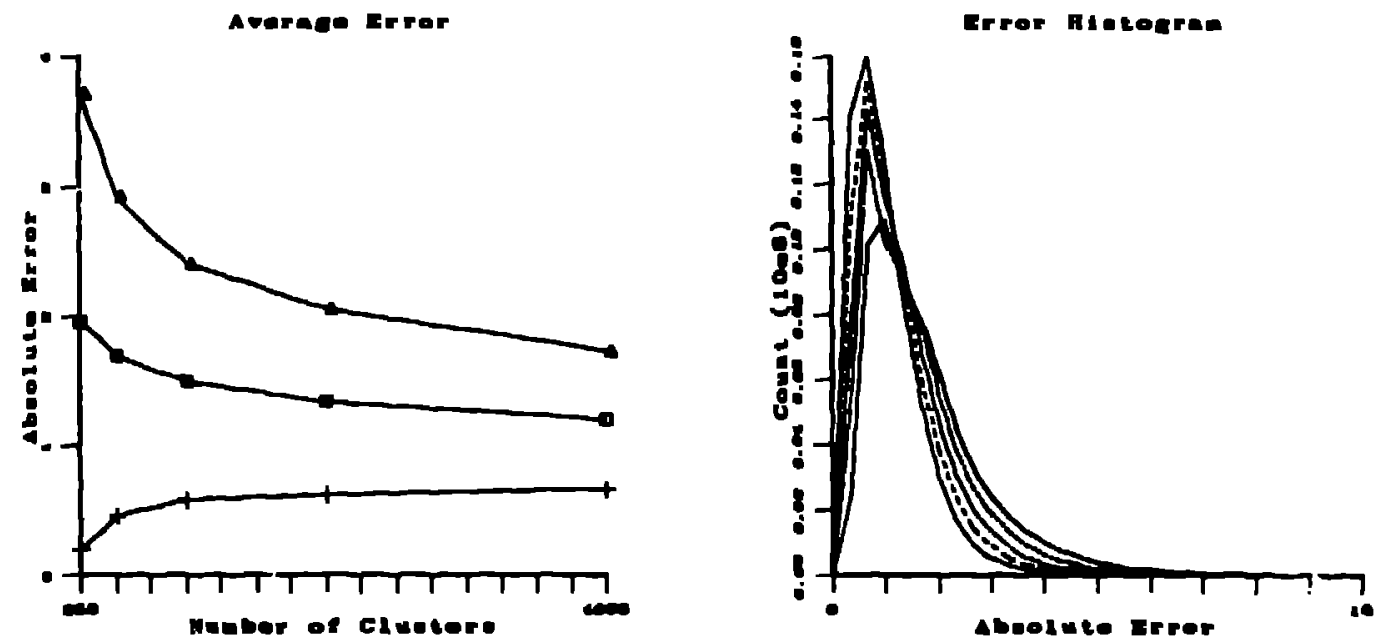

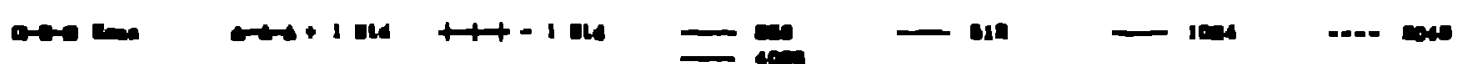

Figure 4: Per Pixel Errors for 800-by-800 Subsection of Moscow Seene

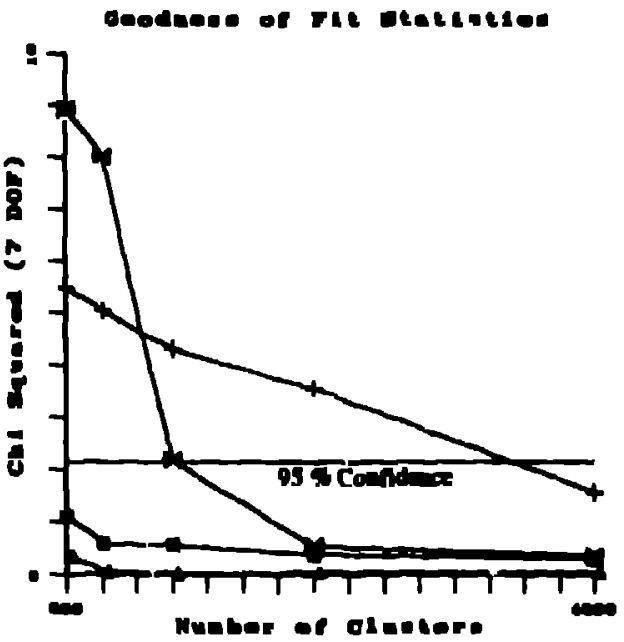

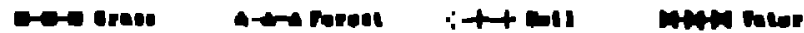

Figure 5: ('hi--Squnred ciuodumen of Fit for "? IX)F 
as if they were to be used in a traditional supervised classification. We then did a Chi Square goodness-of-fit test to determine what our confidence was that the mean vectors representing the clustered data came from the same process which generated the statistics from the training sets in the original data. The results are shown in Figure 5. A Chi Square test with 7 degrees of freedom has a value of less than 2.83 for greater than $90 \%$ confidence and a value of less than 2.17 for a greater than $95 \%$ confidence. For an image with 4096 clusters all land covers had greater than $95 \%$ confidence. For 256 clusters, the goodness-of-fit values were much worse for the water training sets than for other land covers. The training sets for water were extremely uniform with a variance in each spectral band of less than 1.5. This means that even small differences between mean vectors yield large Chi Square values.

The errors introduced in a fine grain clustering of the multi-spectral data were not large enough to affect a level one land use classification. With 4096 clusters, the clustered image could be used to effectively represent the original data. Each land cover type was identified as easily as with the original image data.

\section{CONCLUSIONS}

Using a clustering method to do a preliminary classification of multispectral data provides data sets that can be rapidly categorized in an interactive fashion. A desktop workstation can be used to manipulate and analyze the preprocessed data in real time. Unlike present uses of clustering, where scientists attempt to find relatively small numbers of clusters in the data, our techniques define a large number of clusters to use. This data contains a relatively small number of unique representative vectors that must be categorized, as compared to millions of pixels in the raw data.

\section{ACKNOWLEDGEMENTS}

This work was performed under a U.S. Government contract (W-7405-ENG-36) by the Los Alarnos National Laboratory, which is operated by the University of California for the U.S. Department of Energy.

\section{REFERENCES}

[1] Paul M. Mather. Computer Processing of Remotely-Sensed Images. St. Edmundsbury Press Ltd., Bury St. Edmunds, Suffolk, 1987.

[2] Robert A. Schowengerdt. Techniques for Image Processing and Classification in Remote Sensing. Academic Press, New York, New York, 1983.

[3] R.O. Duda and P.E. Hart. Pattern Classification and Scene Analysis. Wiley, New York, NY, 1973.

[4] J.T. Tou and R.C. Gonzalez. Pattern Recognition Principles. Addison-Wesley, Reading, MA, 1974.

[5] A.K. Jain and R.C. Dubes. Algorithms for Clustering Daia. Prentice Hall, Englewood Cliffs, NJ, 1988.

[6] Jerome H. Friedman, Jon Louis Bentley, and Raphael Ari Finkel. An algorithm for finding best matches in logarithmic expected time. ACM Tmnsactions on Mathematical Software, 3(3):209-226, 1977.

[7] J.L. Bentley, B.W. Weide, and A.C Y Yao. Optimal expected-time algorithms for closest point problems. AC $M$ Transactions on Mathematical Software, 6:563-580, 1980.

[8] M.E. Hodgoon. Reducing the computational requirements of the minimum-distance classifier. Remote Sensing of Environment, 25:117 128, 1988.

[9] Jeromn H. Friedman, Forest Baskett, and Leonard J. Shustek. An algorithm for finding noarest ncighbors. IEEE Transactions on Computers, pages 1000 1006, Octoher 1975. 